\title{
ASPECTOS DA MODERNIDADE EM SOROCABA: EXPERIÊNCIAS URBANAS E REPRESENTAÇÕES $1890-1914^{*}$
}

\author{
Rogério Lopes Pinheiro de Carvalho
}

Doutorando em História Social-FFLCH/USP

\section{Resumo}

Este texto tem como objetivo examinar as transformações urbanas que ocorrem em Sorocaba, entre o final do século XIX e as primeiras décadas do século XX, no contexto do desenvolvimento industrial da cidade. Particularmente a partir das representações que são elaboradas pelos seus diferentes segmentos e classes sociais, indicando práticas, usos e formas de sociabilidade que se constroem em decorrência desse processo histórico.

\section{Pallavras-Chave}

Sorocaba • República • Urbanização • Modernidade • Representação

\section{Abstract}

This article examines the urban transformations that took place in Sorocaba at the end of the nineteenth and beginning of the twentieth century, within the context of this city's industrial development. The text focuses on the representations expressed by different social segments and classes, which signal practices, uses, and forms of sociability that were constructed as a result of this historical process.

\section{Keywords}

Sorocaba • Republic • Urbanization • Modernity • Representation

\footnotetext{
* O presente artigo é uma versão modificada e ampliada da comunicação apresentada no XVII Encontro Regional de História - ANPUH - O Lugar da História, realizado de 6 a 10 de setembro de 2004, em Campinas / Unicamp. Constitui parte da pesquisa que está sendo desenvolvida no doutoramento em História, com apoio financeiro da FAPESP.
} 
"Sorocaba deve lembrar-se de que não é mais a Sorocaba dos tempos passados; deve bem considerar que, só no seu perímetro, agazalha actualmente talvez mais de dez mil almas, e que, além das muitas industrias que progridem e florescem no seu seio, o sibilar da locomotiva que a visita diariamente, ha dezoito annos, lhe grita varias vezes ao dia: Avante!" (Diário de Sorocaba - 01/ 02/1893)

\section{I) Rumo à Manchester Paulista - urbanização e industrialização.}

Na sua edição do dia 5 de janeiro de 1905 , o jornal $O 15$ de Novembro anunciava a inauguração dos trabalhos para a construção de uma grande usina hidroelétrica, junto à cachoeira do salto de Itupararanga. Tal obra seria executada pela Empresa Elétrica de Sorocaba, tendo à sua frente Bernardo Lichtenfels Júnior, um dos grandes capitalistas da cidade. ${ }^{1}$

Dias depois o mesmo periódico relata com detalhes as festividades que cercaram o evento, em toda sua magnificência. A cerimônia também se constituiu numa homenagem ao superintendente da Estrada de Ferro Sorocabana, Alfredo Maia. Um nome muito festejado pela elite local, em função de ter revitalizado completamente a companhia, que se encontrava em sérias dificuldades financeiras. A admiração se justificava, afinal a Sorocabana era uma peça vital para o sucesso da expansão industrial da cidade, assim como a construção da usina representaria a garantia para futuros investimentos. Então, nada mais salutar do que comemorar numa mesma solenidade o sucesso da Empresa Elétrica e da Sorocabana. Em meio a esse clima de festa e discursos exaltados, surge a comparação entre Sorocaba e a cidade inglesa de Manchester. A relação é feita por ninguém menos do que o próprio Alfredo Maia, que, agradecendo os obséquios recebidos e num "improvisado e eloqüente discurso" sustentava que dali a não pouco tempo Sorocaba se tornaria a Manchester brasileira. ${ }^{2}$ Tal expressão foi rapidamente encampada pelas lideranças locais, fato decisivo

\footnotetext{
${ }^{1}$ O 15 de Novembro, 05/01/1905.

${ }^{2}$ O 15 de Novembro, 10/01/1905. GASPAR, Antonio Francisco. Sorocaba de ontem crônicas da cidade, Comemoração da $3^{\circ}$ Centenário, Sorocaba [s.n.], 1954, p. 48.
} 
para que a cidade se tornasse conhecida, ao longo do século $\mathrm{XX}$, como a Manchester Paulista. ${ }^{3}$

O presente texto tem como propósito perscrutar alguns aspectos do desenvolvimento urbano da cidade à luz de seu processo de industrialização. Ou seja, examinar como se deu em Sorocaba a relação entre urbanização e industrialização, tomando como ponto de entrada as representações que vão sendo elaboradas pelos diferentes grupos, segmentos e classes sociais.

O conceito de representação é utilizado aqui, fundamentalmente, a partir das considerações realizadas pelo historiador Roger Chartier. Para este autor, o termo representação pode ser tomado como a "pedra angular" da chamada história cultural. ${ }^{4}$ Tal tendência historiográfica surge como uma crítica a certos determinismos - de caráter economicista, por exemplo -, cometidos por pesquisas realizadas no âmbito da história social que, por isso, não estariam dando conta de recuperar outras práticas e sujeitos do passado. Assim, o estudo das representações possibilita a apreensão de ricos pontos de entrada para a decifração e compreensão das sociedades passadas. Sejam eles "um acontecimento, importante ou obscuro, um relato de vida, uma rede de práticas específicas." 5 Não obstante, talvez sejam necessárias algumas qualificações no que se refere ao emprego do termo em vários trabalhos dedicados à história cultural. Uma vez que, apesar de se tratar de um conceito complexo, dada a sua longa traje-

\footnotetext{
${ }^{3}$ É importante salientar que o título de Manchester brasileira não foi exclusivo de Sorocaba. A comparação com a famosa cidade industrial da Inglaterra, ao que parece, estava presente no imaginário de toda a cidade brasileira que passava por um processo de industrialização, particularmente pela instalação de fábricas têxteis. É o caso de Salto, quando inaugurou a sua primeira fábrica de tecidos, em 1875. Nessa época a localidade era um bairro pertencente à cidade de Itu, interior de São Paulo. Desde a instalação dessa fábrica "tanto os jornais ituanos como os de São Paulo previam sua transformação numa pequena "Manchester Paulista". ZEQUINI, Anicleide. O quintal da fábrica: a industrialização pioneira do interior paulista Salto - SP, séculos XIX e XX. São Paulo: Annablume; Fapesp, 2004, p. 89. Outra cidade a ganhar tal cognome foi Juiz de Fora, graças à instalação de uma grande fábrica têxtil, em 1898. HARDMAN, Francisco e LEONARDI, Victor. História da indústria e do trabalho no Brasil (das origens aos anos vinte), $2^{a}$ ed. São Paulo: Editora Ática, 1991, pp. 127-128.

${ }^{4}$ CHARTIER, Roger. A história cultural - Entre práticas e representações. Tradução: Maria Manuela Galhardo, Lisboa: Difel, 1988, pp. 23-25.

${ }^{5}$ CHARTIER, Roger. O mundo como representação. Estudos Avançados - USP. São Paulo, vol. 5 - no 11, janeiro / abril - 1991, p. 177.
} 
tória, remontando, pelo menos, à Idade Média, e de todas as implicações de sua apropriação recente por essa nova historiografia, ligada por sua vez a já célebre crise do conhecimento histórico (crise epistemológica) ${ }^{6}$, a sua utilização, geralmente, não tem sido acompanhada de uma reflexão à altura de sua importância. Nesse sentido, em meio a certas imprecisões conceituais, corre-se o risco de transformar as representações em medida de todas as coisas, ou seja, pensar o texto histórico apenas como um artefato lingüístico, sem qualquer referencialidade externa, trocando-se um reducionismo a "tirania do social", por outro "a tirania do cultural". ${ }^{7}$ O próprio Chartier oscilou entre posturas mais ou menos céticas, afastando-se, a nosso ver felizmente, desse radicalismo cético, ao afirmar que a história produz um conhecimento "controlável e verificável", sendo ainda capaz de separar o verdadeiro do falso, em que pese todas as necessárias mediações. ${ }^{8}$ A partir da influência de Mauss e Durkheim, como também de Pierre Bourdieu, Chartier passa a considerar as representações coletivas articuladas ao mundo social. Dessa forma, as representações coletivas "incorporam nos indivíduos as divisões do mundo social e estruturam os esquemas de percepção e de apreciação a partir dos quais estes classificam, julgam e agem". . Ao historiador caberia uma dupla operação: "constituir como repre-

\footnotetext{
${ }^{6}$ Sobre a crise do conhecimento histórico, dentre vários estudos, ver: COSTA, Emília Viotti A dialética invertida: 1960-1990. Revista Brasileira de História: Brasil 1954-1964. São Paulo: ANPUH / Marco Zero, vol. 14, n.27, 1994, p. 9-26. FONTANA, Josep. História depois do fim da história. Tradução: Antonio Penalves Rocha. Bauru: Edusc, 1998. SALIBA, Elias Thomé. As luzes e as fadas: marxismo e tendências da historiografia. In: COGGIOLA, O. (Org.) Marx e Engels na história. São Paulo: Xamã, 1996. ZAGORIN, Perez. History, the reference, and narrative. History and theory: studies in the philosophy of history, v. 38, n. 1. 1999, p. 1-24.

${ }^{7}$ CARDOSO, Ciro Flamarion. Introdução: uma opinião sobre as representações culturais. In: Representações: contribuições a um debate transdisciplinar. CARDOSO, Ciro Flamarion e MALERBA, Jurandir (orgs.), Campinas: Papirus Editora, 2000, p. 10-19. FALCON, Francisco. História e representação. In: Representações: contribuições a um debate transdisciplinar. Op. cit., p. 42.

${ }^{8}$ CHARTIER, Roger. A história hoje: dúvidas, desafios, propostas. Estudos Históricos, Rio de Janeiro, vol. 7, n' 13, 1994, p. 111.

${ }^{9}$ CHARTIER, Roger. Idem, p. 107. Ou, como escreve Bourdieu: "As diferentes classes e frações de classes estão envolvidas numa luta propriamente simbólica para imporem a definição do mundo social mais conforme os seus interesses, e imporem o campo das tomadas de posições ideológicas reproduzindo em forma transfigurada o campo das posições sociais.” BORDIEU, Pierre. O poder simbólico. Tradução: Fernando Tomaz. Lisboa: Difel, 1989, p. 11.
} 
sentações os vestígios, sejam de que tipo forem - discursivos, iconográficos, etc., - que indicam as práticas constitutivas de qualquer objetivação histórica. Estabelecer hipoteticamente uma relação entre séries de representações, construídas e trabalhadas enquanto tais, e as práticas que constituem o seu referente externo. (grifo nosso)" ${ }^{\prime 10}$.

Uma hipótese a ser trabalhada é pensar a especificidade da história urbana de Sorocaba, num momento em que a cidade - pelo menos no que se refere aos grandes centros -, se problematiza, gerando novas demandas e necessidades. A questão, portanto, é verificar se para além das transformações por que passam as maiores cidades brasileiras (Rio de Janeiro e São Paulo, por exemplo), muitas dessas manifestações da modernidade da Belle Époque já poderiam se fazer sentir em algumas cidades do interior.

Sem dúvida aqueles anos iniciais do século XX foram auspiciosos para o crescimento econômico da cidade. Com efeito, Sorocaba já se inseria num contexto de industrialização que se adensava desde a década de 1890, caracterizado pela instalação, em especial, de indústrias têxteis. Houve um certo refluxo durante os anos de 1897 e 1904, por conta de instabilidades no cenário internacional, bem como pela crise de superprodução do complexo exportador cafeeiro (significando a baixa nos preços do café), e da difícil situação financeira do Estado brasileiro. Contudo, a partir de 1905, o ritmo de crescimento é retomado. ${ }^{11}$ Mas, segundo matéria publicada na imprensa sorocabana no início de 1903, já no ano anterior o panorama começava a se modificar favoravelmente para a indústria nacional. Assim, em Sorocaba, reabriu-se uma antiga e tradicional fábrica de chapéus, sob nova direção; uma nova fábrica de bebidas é inaugurada; a fábrica de tecidos Santa Maria retoma suas atividades, tendo inclusive encomendado novos equipamentos que já se encontravam no porto de Santos. Além disso, o Banco União, proprietário da indústria de estamparia e chitas Votorantim, firma contrato para a construção de um grande edifício,

\footnotetext{
${ }^{10}$ CHARTIER, Roger. A história cultural - entre práticas e representações. Op. cit., pp. 16-18, 87.

${ }^{11}$ ARIAS NETO, José Miguel. Primeira República: economia cafeeira, urbanização e industrialização. In: FERREIRA, Jorge e DELGADO, Lucilia de Almeida Neves (org.) O Brasil Republicano - o tempo do liberalismo excludente - da proclamação da República à Revolução de 1930. Rio de Janeiro: Civilização Brasileira, 2003, pp. 216-217. MELO, João Manuel Cardoso de. O capitalismo tardio, $3^{\text {a }}$ ed. São Paulo: Brasiliense, 1984, pp. 133 e 140.
} 
onde seriam instaladas máquinas de fiação e tecelagem, o que a tornaria o maior estabelecimento do gênero na América Latina. Por tudo isso, escreve o autor da reportagem: "As nossas indústrias apparecem, pois, novamente prosperas, novamente recompensadas; e o bom êxito que os productos da industria sorocabana encontram nos principais mercados, nos faz suppor, com justa razão, que, brevemente a nossa cidade saberá attrair sobre si a attenção de homens de iniciativa e de negócios que desejem empregar capitaes avultados em outras industrias rendosas, mas que entre nós, ainda não estão exploradas." ${ }^{2}$

Em 1904, a revista São Paulo Illustrado, numa edição especial sobre a cidade de Sorocaba, salienta o clima de otimismo, escrevendo na apresentação do número: "Sorocaba merece hoje nossa homenagem. É uma cidade histórica, progressista, industrial, é a terra essencialmente trabalhadora, uma colméia em atividade constante." ${ }^{13}$ A reportagem visita as principais fábricas da cidade, constatando in situ seu desenvolvimento econômico.

Portanto, podemos compreender a empolgação trazida pela perspectiva da construção de uma usina hidroelétrica, uma vez que essa supriria a crescente demanda de força motriz por parte das indústrias em expansão, além de se constituir numa forma de energia "muito mais barata e segura que o uso direto da água e as dispendiosas máquinas a vapor utilizando carvão." ${ }^{14}$

Energia elétrica era uma antiga reivindicação dos dirigentes sorocabanos, e sua implementação foi marcada por uma série de contratempos, avanços e recuos. A primeira tentativa ocorreu em 1895, através de contrato realizado entre a Câmara Municipal e os irmãos Vicente e João de Oliveira Lacerda. Ficava estipulado que os serviços começariam a funcionar dali a dois anos, porém, os Lacerda enfrentaram dificuldades de toda a monta, sendo a principal delas as duas epidemias de febre amarela que grassaram sobre o município em 1897 e 1900. Os prejuízos foram consideráveis, além das vítimas, houve a quase total paralização das atividades comerciais e o fim da boa fama que gozava o clima da cidade, como lugar aprazível para visita e restabelecimento da saúde. Nesse ambiente conturbado, os Lacerda foram conseguindo prorrogações para inauguração, que deveria ocorrer em primeiro de janeiro de 1900, justamente no momento de eclosão da última epidemia. A cidade

\footnotetext{
${ }^{12}$ O 15 de Novembro, 08/01/1903.

${ }^{13}$ S Paulo Illustrado, Anno II, abril de 1904, n²4.
} 
continuava sem luz elétrica. A iluminação começou efetivamente a funcionar, porém, permaneceu precária ao longo de todo o ano e, assim, em dezembro, a Câmara considera o contrato caduco. O espólio foi passado, em 1901, para A. J. Byington, melhorando consideravelmente o serviço de iluminação. Em 1902 obtém o privilégio para construção de uma usina hidroelétrica, pois estava patente a insuficiência da usina a vapor existente na cidade em atender o aumento da demanda. O privilégio foi passado para Bernardo Litchtenfels, em 1905, quando se iniciam os trabalhos de construção mencionados acima. A empresa canadense-anglo-americana Light \& Power obtém os direitos de concessão em $1911 .{ }^{15}$

É importante salientar que melhoramentos como força e luz, abastecimento de água e canalização de esgotos, representavam uma nova concepção do espaço urbano que não se inicia com a República, remontando, mais precisamente, às últimas décadas do Império.

Numa perspectiva mais ampla, essas novas idéias podem ser relacionadas às transformações que passam a ocorrer no país ao longo da segunda metade do século XIX; fatos como o fim do tráfico de escravos, a nova política tarifária, a lei de terras, a expansão da lavoura cafeeira, gerando capitais para o país, bem como a introdução de novas técnicas e serviços como o telégrafo, a navegação a vapor, a ferrovia e as primeiras tentativas mais sistemáticas de instalação de manufaturas, representam uma maior inserção do país nos fluxos da modernidade do século XIX, ou seja, da expansão do capitalismo internacional. Esses fatores proporcionam um aumento, ainda que incipiente, do mercado

\footnotetext{
${ }^{14}$ STEIN, Stanley J. Origens e evolução da indústria têxtil no Brasil - 1850-19150. Tradução: Jaime Benchimol. Rio de Janeiro: Editora Campus, 1979. p. 108.

${ }^{15}$ ALMEIDA, Aluisio de. Sorocaba - 3 séculos de história, Itu: Editora Ottoni, 2002. pp. 376-378; A luz elétrica e a tragédia dos irmãos Lacerda em 1899. Segundo Aluísio de Almeida, a Light ao assumir a concessão de luz e força, passa a construir uma nova Represa em Itupararanga, em 1912 mais de 2000 operários estavam envolvidos. "Era um fervet opus medonho. Vieram até hindus, que não se habituaram.” ALMEIDA, Aluisio de. $O p$. cit., p, 378. Todo esse episódio que marca a chegada da Light em Sorocaba ainda merece um estudo mais acurado. Mas é possível afirmar que eventos como as obras em Itupararanga se constituem perfeitamente naquele fenômeno que Foot Hardman chama de drama da modernidade, significando choque de temporalidades, destruição sistemática de espaçostempos insulados, aceleração dos ritmos das trocas simbólicas, velocidade crescente no processo internacional de inovação e transferência de técnicas. HARDMAN, Francisco Foot. Antigos Modernistas. In: NOVAES, Adauto. (org.) Tempo e História. São Paulo: Secretaria Municipal da Cultura / Cia. das Letras, 1996, pp. 293-294.
} 
interno que, por sua vez, repercutirá positivamente no desenvolvimento urbano das cidades, em grande parte modorrentas, do Império em geral e da província em particular. ${ }^{16}$ Em Sorocaba, mais ou menos no período entre 1870 e 1890 , começam a surgir uma série de novas instituições, como o gabinete de leitura, escolas leigas, lojas maçônicas, além de ocorrer um aumento na circulação de livros e jornais. ${ }^{17}$

Com isso, as novas concepções sobre como deveria ser o ordenamento urbano começam a vicejar de forma mais significativa, inclusive em algumas cidades do interior. Especialmente a partir da década de 1870, segmentos das elites e das camadas médias (advogados, jornalistas e médicos) do país passam a se pautar por um discurso modernizador que significa, grosso modo, ser republicano, abolicionista, defender a imigração européia, apoiar as inovações tecnológicas, a maior laicização da sociedade e um uso mais racional e higiênico da cidade. No caso de Sorocaba, as mais recentes pesquisas têm indicado que esse discurso modernizante é encampado por setores representativos da cidade, estes, dessa forma, começam a considerar o tradicional comércio de muares como um empecilho aos melhoramentos de que a cidade necessita. ${ }^{18}$ Tal fato não se dá sem tensões uma vez que a maior parte da arrecadação de impostos

${ }^{16}$ COSTA, Emilia Viotti. Urbanização no Brasil no século XIX. In: Da Monarquia à República: momentos decisivos. São Paulo: Editorial Grijalbo, 1977. pp. 193-194. SODRÉ, Nelson Werneck. História da burguesia brasileira 3. ed. Rio de Janeiro: Civilização Brasileira, 1976. pp. 108-117. Sobre esse contexto escreve Caio Prado Jr.: "a antiga colônia segregada e vegetando na mediocridade do isolamento, se moderniza e se esforça por sincronizar sua atividade com a do mundo capitalista contemporâneo." História econômica do Brasil. 20. ed. São Paulo: Brasiliense, 1977, p.195

${ }^{17}$ MARTINS, Ana Luiza. Gabinetes de leitura da província de São Paulo: a pluralidade de um espaço esquecido (1847-1890), Dissertação de Mestrado, São Paulo: FFLCH-USP, 1990, pp. 70-71.

${ }^{18}$ Esses setores especificamente ligados a um projeto liberal, que se tornou ainda mais ativo com a formação do núcleo republicano em 1873, não se cansavam de apontar para os entraves causados pela feira no que dizia respeito aos melhoramentos urbanos na cidade, como calçamento, iluminação e abastecimento de água. Portanto, "o trânsito de animais, além de desgastar as ruas do centro da cidade, era uma ameaça à salubridade pública, dentre outros motivos, pelo uso que os tropeiros tinham de fazer do rio Sorocaba. O comércio de animais também foi colocado como um entrave ao desenvolvimento da cultura de algodão e visto como fonte de desordens, gerando o aumento dos jogos com apostas e prostituição e dos roubos, assaltos e crimes." CHIOVITTI, Nanci. Discursos do progresso: Sorocaba e o fim da feira de muares. Dissertação (Mestrado) - Instituto de Filosofia e Ciências Humanas, Universidade de Campinas, Campinas, 2003, pp. 120-121. 
e da movimentação comercial da cidade ainda se dava em função do comércio de animais. Há um desejo de diversificação econômica, dada a fragilidade de uma economia exclusivamente dependente do comércio de animais. Na década de 1860 ocorre a expansão da cultura do algodão, incentivada pela paralisação do mercado norte-americano por causa da Guerra da Secessão. Em 1875 é inaugurada a Estrada de Ferro Sorocabana, visando estimular ainda mais a produção e exportação do algodão. Entretanto, já em meados da década os Estados Unidos retomam sua produção e a lavoura entra em crise; nesse momento o comércio de muares já não era satisfatório tanto do ponto de vista econômico quanto das novas orientações urbanas, pautadas pelos preceitos estéticos e de salubridade. A ferrovia é inaugurada num momento de incertezas, uma das saídas encontradas passa a ser o desenvolvimento da indústria têxtil. ${ }^{19}$

Um editorial redigido pelo escritor Júlio Ribeiro, poucos dias antes da inauguração da Sorocabana, deixa patente tal preocupação. ${ }^{20}$ Ribeiro reclama dos pesados encargos que se abatem sobre a lavoura algodoeira. Uma alternativa seria justamente o estabelecimento de manufaturas, o que daria real valor à matéria prima e desenvolveria a produção. E, nesse sentido, escreve: "Sorocaba acha-se nas mais lisonjeiras circunstancias de possuir uma manufatura de tecidos de primeira ordem, que possa rivalisar com qualquer império, e talvez até com as boas da Europa ou dos Estados Unidos." 21

As condições eram realmente favoráveis, como escreve o autor de Padre Belchior de Pontes, a cidade era uma das grandes produtoras de algodão, havia considerável disponibilidade de recursos hídricos e quedas d’água - as potencialidades do salto de Itupararanga em Votorantim, a poucos quilômetros da cidade, já eram sobejamente conhecidas, havia ainda mão de obra abun-

\footnotetext{
${ }^{19}$ MARTINS, Ana Luiza. Op. cit., BADDINI, Cássia. Sorocaba no império - comércio de animais e desenvolvimento urbano. São Paulo: Annablume / Fapesp, 2002. CHIOVITTI, Nanci. Op. cit., CANABRAVA, Alice. O algodão em São Paulo - 1861-1875. $2^{\mathrm{a}}$ ed. São Paulo: T.A. Queiroz, Editor, 1990, p. 274.

${ }^{20} \mathrm{O}$ jornal se chamava Gazeta Commercial e seu dono era exatamente Matheus Maylasky, um dos grandes capitalistas da cidade, envolvido com os negócios do algodão e também comércio de muares, tendo sido o presidente da Companhia Sorocabana. Assim, Maylasky funda o jornal para defender a sua liderança frente à Companhia. Para isso não poupa esforços e muito menos dinheiro, adquirindo no Rio de Janeiro um moderno prelo Alouzet e chamando para a redação do jornal o escritor Júlio Ribeiro. ALMEIDA, Aluisio de. Op. cit., pp. 297-298.

${ }^{21}$ Gazeta Commercial, 04/07/1875.
} 
dante, em decorrência da imigração; e, além disso, com a Estrada de Ferro se solucionaria as dificuldades de transporte, sem contar que a cidade já se encontrava localizada próxima às grandes praças comerciais, como São Paulo.

No entanto, a trajetória para o advento de uma grande manufatura têxtil na cidade foi um tanto quanto tortuosa, ocorreram várias tentativas fracassadas ao longo da década de 1870, isso a despeito de se ter organizado, pelos mesmos dirigentes da Companhia Sorocabana, uma sociedade anônima denominada "Indústria Sorocabana", visando justamente à criação de uma fábrica de tecidos. ${ }^{22}$

Finalmente, em 1882, é fundada a fábrica têxtil Nossa Senhora da Ponte, por iniciativa de Manoel José da Fonseca, um iminente comerciante de tecidos da cidade. Tal fato se configura como um marco no processo de industrialização local, uma vez que propicia o incentivo para a instalação de novas fábricas.

Trata-se, então, de averiguar no caso de Sorocaba, as relações entre o desenvolvimento urbano da cidade e seu processo de industrialização. Evidentemente não se pode traçar uma relação mecânica entre urbanização e industrialização no contexto brasileiro. Muitas cidades, como São Paulo, por exemplo, tiveram seu crescimento, num primeiro momento, pautado pelo capital comercial. Por outro lado, a cidade parece ser o espaço privilegiado para o desenvolvimento industrial, pelas suas condições estruturais e pela concentração de mão de obra, bem como por se constituir num mercado de consumo privilegiado. Portanto, como escrevem Foot Hardman e Victor Leonardi, "se historicamente, as cidades preexistiam às indústrias, ocorreria que, a partir do momento em que o capital financeiro chegou a dominar todas as demais atividades econômicas, ele passou também a determinar toda expansão urbana, desde os aspectos econômicos até sócio-políticos e culturais.”23

\footnotetext{
${ }^{22}$ BADDINI, Cássia. Op. cit., p. 269.

${ }^{23}$ HARDMAN, Foot e LEONARDI, Victor. Op. cit., pp.121-122. Há ainda a especificidade de cidades que nasceram em função do estabelecimento de uma unidade fabril, ou seja, nestes casos, a fábrica antecedeu o núcleo urbano. É o caso da cidade de Salto, estudado por Anicleide Zequini. Op. cit. Também apresentam um contexto semelhante as cidades de Americana e Votorantim. Esta última surgiu em torno da fábrica Votorantim, instalada em 1890, e da respectiva vila operária, tornando-se, na sua origem, um distrito de Sorocaba.
} 
Nesse sentido, a cidade pode ser pensada como o espaço de realização e construção da modernidade. ${ }^{24}$ Como já mencionado acima, para boa parte de elite republicana - veiculada de alguma forma a chamada "Geração 1870", a cidade moderna deveria se pautar pelos preceitos de circulação, higiene e estética (aformoseamento), esse modelo tomava como referência, fundamentalmente, as reformas urbanas realizadas na Europa durante o século XIX, em particular aquelas implantadas no período de Napoleão III em Paris; tendo como propósitos principais a segregação espacial, aumentando as formas de controle social por parte da burguesia agora no poder e a ampliação dos espaços de circulação de pessoas e mercadorias. O advento da República representa o aprofundamento do desejo de modernização do país, uma vez que, segundo os próceres do novo regime, a nação se encontrava livre das amarras do Império com suas instituições carcomidas. Como indica Foot Hardman, a retórica dominante é pautada pela ânsia do progresso. ${ }^{25}$

Em Sorocaba, ao longo de toda a década de 1890, a imprensa publica matérias sobre a necessidade de melhoramentos urbanos e medidas embelezadoras, como a construção de parques e a arborização dos logradouros. Uma série de atos institucionais sinaliza esse anseio de modernização. A partir de 1896, os jornais da cidade começam a editar os relatórios dos prefeitos (à época ainda

\footnotetext{
${ }^{24}$ PESAVENTO, Sandra Jatahy. O imaginário da cidade - visões literárias do urbano. $2^{a}$ ed. Porto Alegre: Ed. Universidade/UFRGS, 2002, p. 158. O termo modernidade é, como tantos outros, polissêmico e possui alto grau de dispersão, aqui, ele remete ao processo histórico pautado pelo desenvolvimento tecnológico, industrialização e constituição da relação social capitalista, bem como o seu espraiamento pelo planeta. O que resultará em uma série de representações, novos hábitos e estilos de vida. A cidade é o locus no qual todas essas transformações se farão sentir de maneira mais intensa, tanto pelas modificações do espaço urbano, como também da perspectiva subjetiva e sensorial. A bibliografia sobre o tema é vasta, mencionamos apenas algumas referências: LEFEBVRE, Henri. Introdução à modernidade - Prelúdios. Tradução: Jehovanira de Souza. Rio de Janeiro: Paz e Terra, 1969.; LÖWY, Michel. A escola de Frankfurt e a modernidade; Novos Estudos CEBRAP, São Paulo, n. 32, p. 119-127, março 1992. BERMAN, Marshall. Tudo que é sólido desmancha no ar. Tradução: Carlos Moisés e Ana Maria Ioriatti. São Paulo: Cia das Letras, 1986. SINGER, Ben. Modernidade, hiperestímulo e o início do sensacionalismo popular. Tradução: Regina Thompson. In: CHARNEY, Leo e SCHWARTZ, Vanessa (orgs.), O cinema e a invenção da vida moderna, São Paulo: Cosac \& Naify Edições, 2001.
}

${ }^{25}$ HARDMAN, Francisco Foot. Trem Fantasma - a modernidade na selva. São Paulo: Cia das Letras, 1988, p. 91. 
conhecidos como intendentes), documentando as atividades realizadas pelo poder executivo $^{26}$. A Câmara Municipal, por sua vez, a partir de 1894, promulga uma série de leis que expressam as novas concepções urbanas. Como o código de novas posturas, regulamentos para o matadouro e o mercado municipal, regulamento para o lançamento e arrecadação de impostos de indústrias e profissões, e ainda, normas para a construção de edifícios ou habitações.

Em 1915, é publicada a Codificação de Leis da Câmara Municipal, praticamente vinte anos após as primeiras posturas republicanas de 1894; sua leitura nos permite ter uma visão das concepções urbanas pretendidas pelos dirigentes da cidade. Por exemplo, há artigos proibindo que construções sejam cobertas com sapé, ou ainda o emprego de rótulas, postigos, vidraças, venezianas ou cancelas que abram para fora e atrapalhem o trânsito público. Capítulos inteiros são dedicados à higiene das ruas, habitações, alimentação e moléstias transmissíveis. Chama atenção também a seção referente aos assuntos policiais, na qual o artigo 101 traz uma série de proibições, dentre elas: fazer algazarra e vozeria ou rumor que perturbe o sossego público; andar pelos passeios com cestos, balaios, tabuleiros; amarrar animais em postes de iluminação e telefones; deixar vagando pelos logradouros da cidade cabras, vacas, bois, porcos, cavalos, burros e galinhas; mendigar pelas ruas da cidade; realizar batuques, tambaques, cateretês e divertimentos semelhantes dentro do perímetro urbano. ${ }^{27}$

A modernização pretendida significava, por conseguinte, e dentre outros aspectos, negar uma série de práticas populares arraigadas desde os tempos coloniais, passando pelo período imperial, e que no contexto sorocabano, estavam intimamente relacionadas com o comércio tropeiro. Essas codificações podem ser compreendidas como tentativas de controlar, domesticar e, se possível, eliminar costumes que, supostamente, não estariam em harmonia com os modernos paradigmas urbanísticos. Nesse sentido, elas podem ser enten-

\footnotetext{
${ }^{26}$ A obrigatoriedade da apresentação do relatório pelo intendente é estipulada na Lei $\mathrm{n}^{\circ}$ 63, promulgada pela Câmara Municipal de Sorocaba, em 19 de dezembro de 1904. Essa lei trata da organização do município e das atribuições dos poderes legislativo e executivo. O artigo 19 trata das competências do intendente, dentre elas, como indica o item L: "apresentar á Camara annualmente relatorio circunstanciado de sua gestão e super intendencia". O 15 de Novembro, 22/12/1904.

${ }^{27}$ Codificação de Leis da Câmara Municipal de Sorocaba (1914-1915). Sorocaba: Typographia Quinze de Novembro, 1915.
} 
didas também como imagens do desejo, pois não se tentaria proibir algo que não mais existisse, o que pode nos dar pistas acerca dos tensionamentos existentes entre os diferentes setores sociais no âmbito da cidade.

Portanto, a análise desses códigos e posturas municipais nos permite apreender a dinâmica entre a "cidade real" e a "cidade ideal". Ou seja, as legislações urbanas referem-se a uma cidade projetada, via de regra de acordo com os interesses dos setores dominantes da sociedade; trata-se de uma "concepção de cidade" que vai interagir com as práticas de vários grupos que compõe o espaço urbano - na forma de adaptação, reelaboração ou resistência nas suas mais variadas circunstâncias.

\section{II) Perspectivas e temporalidades da cidade}

O historiador deve ter a preocupação de abarcar as múltiplas visões da cidade, não se limitando apenas as narrativas produzidas pelos produtores do espaço urbano, ou seja, os poderes públicos e seus representantes, mas também buscar a perspectiva do habitante da urbe, do citadino. ${ }^{28} \mathrm{O}$ que significa estar atento para diferentes maneiras de ver e narrar a cidade ${ }^{29}$. Tal procedimento implica uma determinada postura teórica e metodológica que tenha como propósito trazer à tona esses outros olhares. É o caso de se pensar uma história social do cotidiano ou uma hermenêutica do cotidiano, como formula a historiadora Maria Odila Silva Dias, procurando perceber as relações que se estabelecem entre a concretude das experiências cotidianas e o discurso normativo institucional, assim como a multiplicidade de tempos e sujeitos que marcam a nossa realidade cingida pelo processo histórico da modernidade. ${ }^{30}$ No que se refere à relação entre cidade e modernidade, o escritor Edgar Allan Poe foi um dos que, de maneira absolutamente original, nos levaram para a atmosfera densa de impressões e emoções que se dão nos desvãos do cotidiano, ultrapassando, assim, a superficialidade com que os olhares comumente percorrem a

\footnotetext{
${ }^{28}$ RONCAYOLO, Marcel. Cidade. Enciclopédia Einaudi, Religião, volume 8, Lisboa: Imprensa Nacional / Casa da Moeda, 1986, p. 428.

${ }^{29}$ PESAVENTO, Sandra Jatahy. Op. cit., p. 18.

${ }^{30}$ DIAS, Maria Odila Silva. Hermenêutica do quotidiano na historiografia contemporânea. Projeto História - Trabalhos da memória, PUC-SP, n.17, novembro/1998.
} 
fisionomia das cidades modernas. ${ }^{31}$ Daí que mais de um autor relaciona o trabalho do historiador ao do detetive, pois o conhecimento histórico é indireto, indiciário e conjetural. ${ }^{32} \mathrm{O}$ historiador, à maneira detetivesca, coleciona fragmentos do passado, e, muitas vezes, os indícios mais significativos são justamente aqueles considerados de "menor importância, marginais e residuais, [mas] que, contudo, permitirão a decifração do enigma." ${ }^{33}$

O pensador alemão Walter Benjamin também estabelecia essa junção entre o historiador e o detetive. ${ }^{34}$ Para a sua radiografia da metrópole moderna, Benjamin lança mão das técnicas de montagem, executadas justamente através dos fragmentos da história da modernidade. A montagem assume uma importância heurística em sua concepção de história, procurando "erigir, assim, as grandes construções a partir de minúsculos elementos confeccionados de modo nítido e preciso. E mesmo descobrir, na análise do pequeno elemento particular, o cristal do acontecimento total." 35 Tal método, influenciado pelas vanguardas do início do século XX, como dadaísmo, surrealismo, o teatro de Brecht, e mesmo as técnicas do cinema, do jornal e da alegoria barroca, tinham como princípio a montagem como desmontagem, quer dizer, a confecção de outras constelações em contra-partida ou a contrapelo daquelas formuladas pelas elites.

Dentre os procedimentos de montagem empregados pela historiografia benjaminiana temos "a montagem em forma de choque", ela permite a confrontação frente a frente de representações opostas acerca da cidade. A cidade moderna é permeada por visões ambivalentes, sinônimo do progresso burguês e centro de perdição e desigualdades sociais; lugar por excelência do alienante fetiche da mercadoria e espaço de rebeldias e resistências. A montagem pelo choque e contraste confronta as perspectivas exclusivamente enaltecedoras da cidade,

\footnotetext{
${ }^{31}$ SEVCENKO, Nicolau. Perfis urbanos terríveis em Edgar Allan Poe. Revista Brasileira de História. Vol. 5, no 8/9, set. 1984 / abr. 1985, pp. 73-74.

${ }^{32}$ GINZBURG, Carlo. Mitos, emblemas, sinais - morfologia e história. Tradução: Federico Carotti. São Paulo: Companhia das Letras, 1989, p. 157.

${ }^{33}$ PESAVENTO, Sandra Jatahy. Op. cit., p. 20.

34 "Benjamin cita um comentário de Ernst Bloch sobre sua pesquisa: A história mostra o seu distintivo da Scotland Yard." [N3,4]. BENJAMIN, Walter. The Arcades Project. Translated by: Howard Eiland and Kevin McLaughlin. The Belknap Press of Harvard University Press, 1999, p. 463.

${ }^{35}$ Idem., [N2,6] p. 461.
} 
produzidas pelos protagonistas da modernização urbana, ao fazê-lo, propicia o "despertar" para os aspectos mais inquietantes e contraditórios do ambiente citadino. ${ }^{36}$ Já a "montagem como superposição" é especialmente empregada para se efetuar a "radiografia" do imaginário coletivo, são formas de contextualização do espaço urbano. "Assim é que, na cidade, compareceriam, com fragmentos da história ou atores a serem justapostos uns aos outros, a multidão e o flâneur, o povo e o destacado personagem, negros, mulheres, marginais, políticos, becos e avenidas, festas, rituais, cotidianidade e eventos excepcionais." ${ }^{\text {37 }}$

O cenário urbano é caracterizado pela superposição de imagens, palavras, gêneros literários e perspectivas, assim sendo, os memorialistas, higienistas, escritores e cronistas - alguns deles escrevendo para a pequena imprensa, como jornais operários e gazetilhas sobre os mais variados temas -, se constituem, certamente, nas fontes historiográficas mais ricas para a compreensão desses aspectos da cidade.

É o caso de Gêbê, um obscuro e bissexto cronista sorocabano que escreveu apenas alguns meses em um jornal local, em 1914. Seus textos nos permitem vislumbrar um pouco do caráter multidimensional que caracteriza o processo de transformações urbanas em Sorocaba, durante os primeiros anos da República. Sintomaticamente, sua coluna se denomina "Cavação". Esse termo, muito em voga na época, geralmente significava "negócio ou vantagem obtido por proteção ou ilicitamente; ou esforço para obter vantagens ou melhores condições de vida." Porém, creio que no caso das crônicas de Gêbê, o termo pode ser também compreendido como uma investigação atenta do cotidiano da cidade, repercutindo assuntos palpitantes, polêmicos e seus personagens, uma perspectiva quase que completamente ignorada pela imprensa sisuda do período. ${ }^{38}$ Talvez não seja exagero compará-lo a um autêntico flâneur, percorrendo

\footnotetext{
${ }^{36}$ BOLLE, Willi. Fisiognomia da metrópole moderna - representação da história em Walter Benjamin. São Paulo: Fapesp / Edusp, 1994, p. 91. PESAVENTO, Sandra Jatahy. Op. cit., pp. 19-20.

${ }^{37}$ PESAVENTO, Sandra Jatahy. Op. cit., pp. 19-20. Para uma análise acurada das técnicas benjaminianas de montagem ver: BOLLE, Willi. Op. cit., especialmente pp. 88-99. ${ }^{38}$ Os significados do termo "cavação" foram retirados do Dicionário Houaiss da Língua Portuguesa. Rio de Janeiro: Objetiva, 2001, p. 659.
} 
as ruas, praças, teatros e cinemas da cidade, "cavando" material para suas crônicas. Como escreve Benjamin, "a base social da flânerie é o jornalismo." 39

Em um de seus textos Gêbê chama Sorocaba de cidade caipora, pois tudo nela é incompleto, os mictórios na praça central há muito prometidos mas que nunca são feitos, a construção de um relógio público na mesma praça, a rede insuficiente de água e esgotos, uma vez que não atende toda a população e para completar o azar até mesmo a "poderosa canadense" (se referindo a São Paulo Eletric, denominação da empresa canadense-anglo-americana Light \& Power em Sorocaba), deixa a população às escuras. Escreve o autor: "assim é que hontem, ficamos sem luz até as 21 horas mais ou menos: resultado; muita gente boa andou pegando Tatus, nesses buracos que muito "embellezam" as nossas ruas e provam mais um vez os "relevantes" serviços prestados pela nossa prefeitura." ${ }^{40}$ E por falar no estado das ruas, em outro momento, nosso autor reclama da "poeira insuportável" nos logradouros da cidade, em especial em um dos mais importantes, a rua da Penha. Sem receio de ser chamado de "linguarudo" e "falador", Gêbê, representando o Zé Povo, espezinha e cobra providências da prefeitura, terminando sua matéria com um versinho: "Vamos, vamos seu Prefeito / Um banho n’aquelle rua / Pois o pó liquida vidas / E pode ir também a sua." ${ }^{\prime 1}$

Uma de suas crônicas mais felizes se configura como uma interessante "meta-cavação", pois o tema acaba sendo o seu próprio percurso rumo a redação do jornal.

\footnotetext{
${ }^{39}$ BENJAMIN, Walter. Sobre alguns temas em Baudelaire. In: Charles Baudelaire um lírico no auge do capitalismo. Tradução: Hemerson Alves Baptista. vol. 3. $3^{\mathrm{a}}$ ed. São Paulo: Brasiliense, 1994., p. 225.

${ }^{40}$ Diário de Sorocaba, 21/01/1914.

${ }^{41}$ Diário de Sorocaba, 16/04/1914. É importante perceber que o cronista escrevia para um jornal que naquele momento se encontrava em oposição ao poder executivo, o que propiciava uma certa autonomia para realização de críticas ao desempenho do prefeito. Assim, na mesma edição o jornal comentava o problema da poeira nas ruas da cidade: "Um dos grandes fragelos que actualmente nos atormenta é o terrivel pó. / É um horror, ondas de poeira levantavam-se enraivecidas contra os pobres transeuntes que se aventuram sahir a rua. / Quase que já não se pode sahir, devido ao pó... I E á Prefeitura o que faz? Dorme o sonno dos indifferentes... / Que importa a ella que a população inteira morra afogada sob as ondas poeirentas? Em vez de automóvel-irrigador: carroçadas de terra, extrahida de casas velhas, para variar!..."
} 
"Azar de garupa!

Sahi de casa para ir a redação escrever uma boa "Cavação" mas... que azar! Começo a subir a rua Dr. Braguinha, passo no Scaletti, um barulho de criançada, andei pizando no pé d'um e d'outro e felizmente passei. Chego em frente ao Oricchio, outro barulho.

Cincoenta grammophones e todos tocavam a valsa Dirce: é uma composição muito bella, mas também ouvir-se uma cousa só o dia inteiro é demais!!!

Chego na redacção, um rumor parecido com terremoto "inveis" era o Marinoni que estava em actividade.

Resolvi subir direto.

Passo no Ponto, uma forte discussão, barulho de copos, soccos sobre a mesa, uma fumaceira a sahir pela janella. Desconfiei qualquer cousa e approximei-me para syndicar do facto e... palavra que montei n'um porco formidável!

Verifiquei que lá na sala da frente estavam alguns freguezes.

Elles conversavam muito "baixinho" fumavam um cachimbo e de vez em quando:

-Cacacce! Portate uma bottiglia divino.

Eram trez patrícios de Garibaldi, que em franca camaradagem festejavam a tomada de Trípoli e bebiam á saúde do grande Caneva. Adheri á essa patriótica festa.

Fiz um discurso igual aos do P. Mesquita ${ }^{42}$ e logo puz-me ao fresco. Toquei para a sessão do Jury.

Que azar!

Na occasião em que o advogado começou o seu discurso de defeza, subia a rua uma chusma de carros de bois, um gincho fino e impertinente, feria os meus ouvidos, de sorte nada pude ouvir.

Quando eu for Prefeito, acabarei com esses "phantasmas".

O leitor tenha mais um pouco de paciência!" 43

Gêbê, através de sua descrição, nos permite apreender alguns aspectos do cotidiano da cidade. O que dá certo "colorido" ao texto é captação das sonoridades do ambiente urbano. Assim, temos os gramofones e o som das rotativas

\footnotetext{
${ }^{42}$ Trata-se de Pedro de Oliveira Mesquita, naquela época, um conhecido jornalista da cidade.

${ }^{43}$ Diário de Sorocaba, 20/02/1914.
} 
do jornal, a algazarra das crianças, uma animada conversa entre italianos, lembrando a imigração e, finalmente, o barulho irritante dos carros de bois, como um anacronismo naquele cenário. A narrativa é marcada por ambivalências, alguns ícones de modernização, como é o desejo das elites da cidade, e também do cronista, interagindo com os arcaicos meios de transporte, "fantasmas", que nem os mais recentes atos municipais conseguiam fazer desaparecer das ruas.

A cidade efetivamente passa por transformações, mas tal processo é permeado pela forte permanência de paisagens, práticas e características que remetem a épocas passadas. No aspecto arquitetônico, por exemplo, ainda em meados da década de 1950, era possível encontrar na região central da cidade janelas de rótulas, a despeito, como vimos, de sua proibição pelo código de $1914 .^{44}$ É o caso também dos antigos nomes das ruas, algumas delas possuíam denominações deliciosas, tais como rua da Boa Vista de Cima, rua de Baixo, rua da Bica, rua dos Morros, rua da Olaria, Beco do Inferno, Beco dos Prazeres. Muitos desses nomes, característicos dos tempos coloniais e imperiais, teimavam em persistir, já no período republicano. Aspecto que irritava alguns jornalistas, os quais consideravam esses termos anacronismos de muito mau gosto. Como Oliveira Mesquita, já mencionado na crônica de Gêbê, que escreve em 1913: "Em Sorocaba, como em todas as cidades, existem ruas cujos nomes são tão esquisitos quanto ridículos." ${ }^{45}$ Havia ainda certas regiões da cidade que eram conhecidas por expressões pitorescas, em razão de determinadas práticas que ali se realizavam. É o caso de um local conhecido como Pito Aceso, que era, na passagem do século XIX para o XX, um dos arrabaldes da cidade. Nesse lugar, à noite, os escravos tinham o costume de sentar na soleira das casas para conversar e fumar seus cachimbos de barro. Conforme escreve o memorialista Antônio Francisco Gaspar, "como ali não havia lampiões nem luz elétrica, os pitos acesos das velhinhas e velhos de cor, com seus canudos cumpridos, conforme a usança dessa gente, pareciam vagalumes a divagarem na escuridão e foi por isso que esse trecho da atual Praça 9 de Julho ficou batizado com essa alcunha." ${ }^{46}$.

Essa imbricação entre temporalidades e ritmos é uma característica da urbe, como escreve o historiador Bernard Lepetit, "a cidade nunca é absolu-

\footnotetext{
${ }^{44}$ SANTOS, Elina O. A industrialização de Sorocaba - Bases geográficas. São Paulo: Humanitas / FFLCH-USP, 1999, p. 116.

${ }^{45}$ O Jornal, 21/12/1913.

${ }^{46}$ GASPAR, Antônio Francisco. Minhas memórias: Sorocaba - São Paulo - Santos e viceversa período 1896 a 1909, Sorocaba [s.n.], 1967, p. 168.
} 
tamente sincrônica, ela é permeada por cronologias diferentes que se constroem no âmbito do tecido urbano." ${ }^{\text {47 }}$ No caso do período aqui enfocado tais asserções se revelam pertinentes, uma vez que novas concepções sobre o urbano começam a ganhar preeminência, pautadas pela racionalidade do capital, significando o aparecimento de diferentes mercadorias, melhoramentos urbanos e introdução de modernos equipamentos de infra-estrutura, bem como novas atividades e personagens sociais. Por outro lado, ainda se fazem presentes às antigas relações que se davam na cidade imperial, com suas atividades sociais e personagens, de forte caráter patriarcal e escravista.

Cabe, então, inquirir sobre a especificidade e intensidade do desenvolvimento urbano ocorrido na cidade de Sorocaba, nas primeiras décadas republicanas. A cidade continuava monótona como nos tempos do Império - só modificada nos meses das lendárias feiras de muares; e que várias imagens tiradas nos primeiros anos do século XX parecem confirmar? ${ }^{48}$ Ou o processo de industrialização estaria transformando o ambiente urbano, seja do ponto de vista de sua configuração física, cartográfica, seja pela interação de novos e antigos atores sociais com suas práticas respectivas?

\section{III) Manchester Paulista x Moscou Brasileira}

Não há dúvida que o desenvolvimento industrial da cidade trouxe significativas modificações em sua conformação urbana. Assim, já na década de 1880 a população da cidade chegava a mais de 20.000 habitantes, enquanto que uma estatística de 1872 indicava cerca de 12.000 habitantes. Esse adensamento populacional incentivou a instalação de várias fábricas de bens de consumo, como fábricas de cerveja, vinho, licores, massas e café. Na década de 1920 a cidade tinha em torno de 43.000 habitantes. ${ }^{49}$ Além disso, com a industrialização, novos bairros foram formados, nos arrabaldes da cidade, como a vila operária Santa Rosália e a vila de Votorantim, criadas em torno das respectivas

\footnotetext{
${ }^{47}$ LEPETIT, Bernard. É possível uma hermenêutica urbana? In: SALGUEIRO, Heliana Angotti (org.) Para uma nova história urbana. São Paulo: Edusp, 2001, p. 145.

${ }^{48}$ Uma reunião de algumas fotografias tiradas ao longo da primeira metade do século XX, em Sorocaba, pode ser encontrada em: RANGEL, Paulo e RANGEL, Miriam. Máquinas do tempo. Sorocaba: Crearte, 2004.

${ }^{49}$ BADDINI, Cássia. Op. cit., pp. 202-203. SANTOS, Elina O. Op. cit., p. 105.
} 
fábricas de tecelagem. A malha urbana começa a se expandir para muito além de seu histórico núcleo central, ultrapassando as linhas da Estrada de Ferro Sorocabana, rumo a até então quase totalmente desabitada região norte da cidade, surge, dessa forma, bairros povoados por operários que trabalhavam nas fábricas têxteis da região como Nossa Senhora da Ponte e Santo Antônio, esta fundada em 1913, como nas oficinas da Sorocabana.

Não obstante, alguns autores têm apontado, com razão, uma estranha situação acerca da historiografia sorocabana. Em que pese à importância da industrialização para a história da cidade, o que é produzido sobre o tema fica confinado a perspectiva da burguesia local. Quer dizer, trata-se de uma história de caráter quase que exclusivamente apologético. E os operários? Estes pairam num surpreendente esquecimento. Inclusive, há indícios de que a luta de classes resultante desse processo, desembocou numa autêntica luta de representações, pois além da expressão "Manchester Paulista" - aceita e divulgada de bom grado pela burguesia local -, a cidade receberia ainda um outro cognome: "Moscou Paulista" ${ }^{50}$ No entanto, as referências a esse último termo são muito vagas, não ficando claro a época em que surge - talvez ao longo da década de 1920, muito menos se foi cunhado pelos trabalhadores sorocabanos ou pela própria burguesia, neste caso, evidentemente, com um sentido pejorativo. Portanto, se o processo de construção da imagem de cidade industrial está bem documentado, mas, talvez ainda não tão bem estudado como merece; a história operária, por sua vez, é totalmente fragmentada, dispersa e, em seus momentos iniciais, que, paradoxalmente coincidem com o apogeu do primeiro ciclo industrial na cidade - ou seja, o primeiro quarto do século $\mathrm{XX}^{51}$, se encontra quase completamente esquecida.

Nessa questão há ainda um complicador que se relaciona com as radicais transformações ocorridas no âmbito da relação social capitalista, tão intensas quanto aquelas que se deram na virada do século XIX para o XX e que marcaram a chamada modernidade da Belle Époque. Tais modificações trariam a

\footnotetext{
${ }^{50}$ CAVALHEIRO, Carlos Carvalho. Salvadora! Sorocaba: LINC, 2001, p. 16. SILVA, Paulo Celso da. De novelo de linha a Manchester Paulista - Fábrica têxtil e cotidiano no início do século em Sorocaba. Dissertação (Mestrado) Faculdade de Filosofia, Letras e Ciências Humanas: Departamento de Geografia, São Paulo, 1995, p. 66.

${ }^{51}$ LEIS, Nilson. A caracterização do processo de urbanização e industrialização: $O$ caso de Sorocaba. UNISO, Universidade de Sorocaba, v. 21, nº 2, dez./1995. p. 22.
} 
precarização das relações trabalhistas formais, gerando fenômenos como a terceirização, aumento da informalidade e do desemprego. Nesse contexto, muitos autores, de diferentes matizes, têm apontado para o refluxo de uma historiografia social dos trabalhadores, dentre eles, Boris Fausto, autor de um livro clássico sobre o tema: Trabalho urbano e conflito social. ${ }^{52}$ Mas de uma perspectiva crítica não deveria ser o contrário? Pois se vivemos uma era sombria no qual o capital atinge tal hegemonia que se dá ao direito de fazer retroceder muitas das conquistas obtidas a ferro e fogo pela classe trabalhadora, é o caso justamente de não esquecer essa história, ela hoje está em perigo; e como escreveu Walter Benjamin: "Cabe ao materialismo histórico fixar uma imagem do passado, como ela se apresenta, no momento do perigo... O perigo ameaça tanto a existência da tradição como os que a recebem. Para ambos, o perigo é o mesmo: entregar-se às classes dominantes, como seu instrumento... O dom de despertar no passado as centelhas da esperança é privilégio exclusivo do historiador convencido de que também os mortos não estarão em segurança se o inimigo vencer." ${ }^{53}$

A imprensa local reproduz e amplifica a visão da burguesia da cidade. Desse modo, temos matérias eloqüentes sobre a inauguração de estabelecimentos fabris, ou descrições sobre o funcionamento das grandes indústrias têxteis. As contradições sociais são escoimadas e quando se faz menção ao operário é, geralmente, para exaltar as magníficas condições de trabalho das indústrias, inclusive o trabalho infantil: "Vimol-as alli [as crianças] entretidas, diligentes, numa faina suave, que de maneira alguma lhes pode prejudicar as organizações débeis, em vista do diminuto dispêndio de forças que demanda." 54 Ou ainda noticiando as manifestações de solidariedade entre operários e patrões em prol da indústria nacional. ${ }^{55} \mathrm{Um}$ dos textos marcantes para essa construção de pujante cidade industrial foi aquele escrito pelo jornalista Francisco Camargo César, um dos mais importantes da imprensa sorocabana à época,

\footnotetext{
${ }^{52}$ FAUSTO, Boris. Da militância aos showmícios. Folha de São Paulo, São Paulo, 22 fev. 2004. Mais! p. 3.

${ }^{53}$ BENJAMIN, Walter. Magia e técnica, arte e política - Obras Escolhidas, vol. 1. Tradução: Sérgio Paulo Rouanet. São Paulo: Brasiliense, 1986. pp. 224-225.

${ }^{54}$ O 15 de Novembro, 03/09/1899.

${ }^{55}$ O 15 de Novembro, 16/08/1905.
} 
para o Almanch Illustrado de Sorocaba de 1914. No artigo intitulado "Sorocaba Industrial", Camargo César desafia os que duvidam do merecimento do título conferido há quase dez anos, o de Manchester Paulista. Assevera o progresso local e a liderança da cidade no setor industrial, fato que poderia ser verificado por qualquer viajante que por lá chegasse: "A prova dessa verdade tem o viajante que, mesmo de passagem, nota a nossa actividade industrial, actividade essa synthetisada magnificamente na evolução continua de densas espirais de fumo, lançadas pelos respiradouros gigantescos dos estabelecimentos fabris." A visão é idílica: a urbe em sua "febre de progresso industrial", trabalhando sob o lema "pax et labor." 56

Entretanto, em contra-ponto a essas imagens, há a perspectiva da classe trabalhadora, que pode ser verificada através da imprensa operária. E, nas primeiras décadas do século XX, o jornal O Operário, de tendência anarquista, talvez se configurasse como o representante mais importante dessa imprensa.

Num editorial denominado A situação operária, o jornal expressa as agruras do operariado sorocabano: jornadas de trabalho de 13 a 14 horas, péssimas condições de trabalho e os constantes assédios a que eram submetidas as operárias por parte de contra-mestres e auxiliares prepotentes e bajuladores, tudo isso com a conivência dos gerentes e patrões. Por tudo isso o texto termina com a seguinte frase: "Infelizmente é tristissima a situação operária nesta cidade."

O interessante é que através do jornal podemos apreender também uma outra perspectiva do desenvolvimento urbano da cidade. Por exemplo, em algumas edições o periódico publicou uma coluna denominada Sorocaba Progride, tratando de maneira irônica o progresso da cidade. Esses textos abordam temas como o aspecto arquitetônico dos edifícios, as finanças municipais e os melhoramentos urbanos, como higiene, pavimentação e a rede de água e esgotos, como no texto a seguir:

"Sorocaba progride, não há dúvida!

Avança com uma rapidez enorme, pela senda do progresso. Quem poria duvida nestas nossas afirmações? De certo todos os leitores dessa fo-

\footnotetext{
${ }^{56}$ Almanach Illustrado de Sorocaba - Repositório histórico, literário e recreativo com illustrações - 1914 Organizado por Bráulio Werneck, Anno I, Sorocaba: Editado por Typographia Werneck, 1914, pp. 39-43.

${ }^{57}$ O Operário, 31/10/1909.
} 
Iha não tem deixado passar esta coluna sem lerem-na, convencidos como nós estamos, exclamarão ao terminar: Sorocaba progride! Não foi sem nenhum espanto, que ao amanhecer de domingo, logo depois de deixar a cama, nos dirigimos para as torneiras da casa, procurando o precioso líquido para satisfazer as primeiras necessidades higiênicas e as encontramos completamente secas, vazias como nos tempos de estiagem. De balde começamos a machinar a ausência do líquido do Cubatão [reservatório que abastecia a cidade] e não conseguimos adivinhar o que fosse., ${ }^{, 8}$

Assim como nas crônicas de Gêbê, desponta aqui uma visão mais claudicante a cerca dos melhoramentos urbanos e modernização da cidade, que, provavelmente, possuíam um caráter mais postiço e contraditório do que fazia crer as imagens laudatórias publicadas, por exemplo, nos Almanaques Ilustrados e revistas luxuosas das primeiras décadas do século XX, em Sorocaba. No entanto, no âmbito das representações, é notável perceber a força da imagem da cidade como Manchester Paulista. Com efeito, apesar das críticas contundentes à burguesia local, a imprensa operária, pelo menos até os primeiros anos da década de 1910, não negava de todo essa construção simbólica. É o que transparece no trecho de uma reportagem publicada também no jornal O Operário:

"Todos sabem perfeitamente que a vida de Sorocaba, tem seus alicerces na indústria manufatureira de que muito se orgulham os seus filhos aliás com razão, porque nem uma outra cidade do sul, do norte e mesmo do oeste do Estado tem atingido a um desenvolvimento industrial tão considerável como seja a nossa terra, porisso, teremos imenso prazer que as fábricas existentes vão aumentando dia a dia e que muitas outras ainda se construam aqui, para que o nosso progresso material seja cada vez mais acentuado e para que o título de Manchester Paulista de que goza então, nunca, nem por sonho venha um dia a perder."${ }^{, 59}$

Certamente soa estranho que um jornal voltado para a causa operária incorpore uma representação ligada à burguesia local. No momento, podemos

\footnotetext{
${ }^{58}$ O Operário, 08/05/1910.

${ }^{59}$ O Operário, 19/02/1911.
} 
apenas lançar algumas indagações visando à compreensão de tal procedimento. Seria o caso, nesse sentido, de retomar o estudo clássico de Edward Thompson a cerca da classe operária inglesa, no qual pensa a "classe social" não como uma "estrutura" ou "categoria", mas como um fenômeno histórico, algo, portanto, em constante elaboração e reelaboração, assumindo formas variadas em tempos e lugares diferentes. ${ }^{60}$

Tais asserções são importantes uma vez que chamam a atenção para a existência de uma "superestrutura cultural" que aprende a consciência de classe, mas, invariavelmente, com "defasagens e distorções", decorrência justamente das particularidades históricas em que se inserem os atores sociais. ${ }^{61}$

No caso do jornal O Operário, é possível observar outras contradições ou distorções, ainda mais se levando em conta a sua suposta orientação anarcosindicalista. Por exemplo, o apoio declarado a candidatura Hermes da Fonseca, nas eleições presidenciais de 1910. Contudo, outro aspecto ainda mais interessante é o fato do jornal ter lançado mão de anúncios publicitários, algo por si só bastante raro na imprensa anarquista. ${ }^{62}$ Além disso, os donos dos estabelecimentos anunciados eram maçons pertencentes aos quadros da Loja Maçônica mais importante de Sorocaba, a Perseverança III. ${ }^{63}$ Tratava-se, é verdade, de um segmento que à época fazia oposição ao líder do PRP local, Luis Pereira Campos Vergueiro, mas isso não diminui a peculiaridade da situação. E pode, talvez, explicar a utilização elogiosa da expressão Manchester Paulista em suas páginas.

Diante disso, cabe salientar, mais uma vez, a relevância da pesquisa empírica em constante diálogo com certos pressupostos teóricos e metodológicos

\footnotetext{
${ }^{60}$ THOMPSON, Edward P. A formação da classe operária inglesa. Tradução: Denise Bottmann. Rio de Janeiro: Paz e Terra, 1987, pp. 9-12.

${ }^{61}$ THOMPSON. Op. cit., p. 10.

${ }^{62}$ Sobre esse tema escreve Maria Nazareth Ferreira: "Nos raros casos em que se encontravam produtos anunciados, a publicidade aparece acompanhada de recomendações do próprio jornal com relação à utilidade do produto, o que lhe confere um caráter de escolha política. Do mesmo modo, em certos momentos, aparecem recomendações de boicote, de não -consumo de determinada mercadoria (geralmente quando a empresa responsável por tal produto encontrava-se em litígio com seus operários).” FERREIRA, Maria Nazareth. Imprensa operária no Brasil. São Paulo: Editora Ática, 1988, p. 21.

${ }^{63}$ BONADIO, Geraldo. Sorocaba: a cidade industrial (espaço urbano e vida social sob o impacto da atividade fabril). Sorocaba: Edição do autor, 2004, p. 158.
} 
que tenham como preocupação enfocar as tramas urdidas no âmbito do cotidiano. Particularmente se o propósito for o de recuperar episódios ou personagens esquecidos, ou, apreender as múltiplas temporalidades que se constroem no espaço da cidade; com seus diversos atores, elaborando diferentes práticas e representações sociais. 